\title{
Smoking among Lao medical doctors: challenges and opportunities for tobacco control
}

\author{
Sychareun Vanphanom, ${ }^{1}$ Martha Morrow, ${ }^{2}$ Alongkone Phengsavanh, ${ }^{1}$ \\ Visanou Hansana, ${ }^{1}$ Sysavanh Phommachanh, ${ }^{1}$ Tanja Tomson ${ }^{3}$
}

${ }^{1}$ University of Health Sciences, Vientiane, Lao People's Democratic Republic ${ }^{2}$ Nossal Institute for Global Health, University of Melbourne, Melbourne, Australia ${ }^{3}$ Department of Public Health Sciences, Division of Social Medicine, Norrbacka 2nd floor, Karolinska Institutet, Stockholm, Sweden

\section{Correspondence to} Dr Sychareun Vanphanom, University of Health Sciences, Faculty of Postgraduate Studies, Lao PDR, PO Box 7444 Vientiane, Lao PDR vsychareun@gmail.com

Received 8 December 2009 Accepted 3 October 2010 Published Online First 23 November 2010

\section{(2) UNLOCK:}

This paper is freely available online under the BMJ Journals unlocked scheme, see http:// tobaccocontrol.bmi.com/site/ about/unlocked.xhtml

\section{ABSTRACT}

Background Smoking is an increasing threat to health in low-income and middle-income countries and doctors are recognised as important role models in anti-smoking campaigns.

Objectives The study aimed to identify the smoking prevalence of medical doctors in Laos, their tobaccorelated knowledge and attitudes, and their involvement in and capacity for tobacco prevention and control efforts. Methods This was a cross-sectional national survey by a researcher-administered, face-to-face questionnaire implemented at provincial health facilities throughout the central (including national capital), northern and southern regions of Laos in 2007. Both descriptive and inferential statistics were used.

Results Of the 855 participants surveyed, $9.2 \%$ were current smokers and $18.4 \%$ were ex-smokers; smoking was least common in the central region $(p<0.05)$ and far more prevalent in males $(17.3 \%$ vs $0.4 \% ; p<0.001)$. Smoking was concentrated among older doctors ( $p<0.001$ ). Over $84 \%$ of current smokers wanted to quit, and $74.7 \%$ had made a recent serious attempt to do so. Doctors had excellent knowledge and positive attitudes to tobacco control, although smokers were relatively less knowledgeable and positive on some items. While $78 \%$ of doctors were engaged in cessation support, just $24 \%$ had been trained to do so, and a mere 8.8\% considered themselves 'well prepared'.

Conclusion The willingness of doctors to take up their tobacco control role and the lower smoking rates among younger respondents offers an important window of opportunity to consolidate their knowledge, attitudes, skills and enthusiasm as cessation advocates and supports.

\section{INTRODUCTION}

Historical evidence from high-income countries suggests that smoking rates in the general population followed-at some distance in time-increases and decreases in prevalence among doctors. ${ }^{1}$ Doctors are seen as role models by the public, patients and their colleagues, ${ }^{2}$ and as such can act in reducing societal smoking prevalence ${ }^{34}$ and thus contribute to stemming the projected increase in mortality and morbidity from tobacco-related diseases. ${ }^{5} 6$ By contrast, health professionals who smoke 'send an inconsistent message' to patients whom they have urged to quit. ${ }^{7}$

Laos (Lao People's Democratic Republic) is a landlocked South East Asian nation of approximately 6.2 million people, about $27 \%$ of whom live in urban areas. Most recent estimates put life expectancy at birth at 65 years and literacy rates (age $15+$ ) at $73 \%$. Laos is a low-income country, with $32 \%$ of children under 5 malnourished, although economic growth reached $7.5 \%$ per annum in $2008 . .^{8}$ Up to half of district hospitals do not have fully qualified medical doctors. ${ }^{9}$

Smoking prevalence in male doctors at Mahosot University Hospital in the Lao capital, Vientiane, in 2003 was found to be $35 \%{ }^{10}$ In the same year a national survey found $40.3 \%$ of the population were smokers, with rates among males over four times those of females $(67.7 \%$ vs $16 \%){ }^{11}$ This large disparity by sex is found in neighbouring countries, ${ }^{12}$ reflecting gender norms that encourage male smoking and discourage female smoking. ${ }^{13}$ Smith and Leggat argue that convincing the public of tobacco's dangers may be difficult if doctors are smoking, so monitoring their smoking behaviour is important. ${ }^{14}$ Data related to tobacco use patterns, knowledge, attitudes and determinants among health professionals in Laos are scarce. This study was undertaken in 2007 to document Lao doctors' current smoking prevalence, knowledge and attitudes towards smoking as well as control efforts, and to investigate associations between variables.

\section{Methods}

Laos has 17 provinces plus the capital city (a separate administrative entity). The system of formal health service provision is provided by hospitals, primary healthcare (PHC) and vertical programmes. The hospital system comprises facilities at central, regional, provincial and district levels.

Three provinces were chosen purposively in each of the country's geographical zones. Northern provinces included Luangprabang, Oudomxay and Xiengkhouang; southern provinces included Champassack, Saravanne and Attapeu; and central provinces Vientiane province, Khammouane, Savannakhet and Bolikhamsay; Vientiane the capital city (regarded as norm-leading) was also added, to make a total of 10 study sites. Provinces were chosen because of their relatively high population density and greater number of medical doctors; they were diverse in terms of socioeconomic development, with the central region most affluent. Respondents were sourced from provincial hospitals, province-level health departments, and (for Vientiane) the University of Health Sciences (former Faculty of Medical Sciences), four central hospitals and nine centres involved in prevention and control of diseases. District hospitals were excluded owing to low numbers of medical doctors

The sampling frame for each province/capital city comprised a full list of all fully-trained medical 
doctors in these facilities or organisations. The list numbered 1060 across all provinces. Each doctor on the list was invited to participate. Researchers administered a face-to-face structured questionnaire that was a modified version of WHO's Global Health Professionals Survey. ${ }^{15}$ The instrument included questions on sociodemographics; smoking knowledge, attitudes and practices; and intention to participate in tobacco control. Sociodemographic characteristics covered age, sex, ethnicity, religion, residency, qualifications and years of experience. Knowledge covered tobacco's health, social and environmental impacts. Attitudes were ascertained from responses to 15 questions covering views on anti-smoking campaigns, banning of cigarette advertising, health warnings, pricing of cigarettes, doctors as role models, promotion of smoke free zones, cessation support and integration of tobacco concerns into curriculum or training. Questions about intention to participate in tobacco control activities, and the smoking environment at their workplaces were also asked. Information on smoking status and consumption, age of initiation, quit attempts, expenditure on tobacco and exposure to secondhand tobacco smoke was also gathered.

For knowledge, true or false questions were asked. A Likert scale of 4 scores was used to measure the questions concerning attitudes $(1=$ strongly disagree, $2=$ disagree, $3=$ agree and $4=$ strongly agree).

The eight interviewers had medical backgrounds from the Postgraduate Studies and Research Department, University of Health Sciences. A pilot study was conducted with lecturers, pharmacists and dental health professionals from the University of Health Sciences, after which the questionnaire was modified. The fieldwork was supervised by the first author. Ethical clearance was obtained from the National Ethical Review Board for Research, Ministry of Health, Vientiane (ref No 132/NECHR). Informed consent was obtained from each respondent.

\section{Data analysis}

The data were checked for completeness and validity and entered into Epilnfo, then analysed using SPSS 10.0. Frequency distributions were used to describe the data.

Smoking status among doctors was grouped into three categories: (1) current smokers (occasional and daily smokers at the time of the study); (2) ex-smokers (former smokers who had stopped); (3) never-smokers (never tried a cigarette in their lifetime).

Bivariate analysis was used to measure associations between selected variables by region and by smoking status, with statistical significance based on the $\chi^{2}$ and Fisher's exact test for independence for categorical variables, and a test for continuous variables.

Adjusted ORs and 95\% CIs were estimated using logistic regression to identify factors associated with current smoking after controlling for confounding. Only male doctors were included in the multivariate analysis because of the small number of female smokers (two). The factors adjusted include age, education, duties, provision of treatment, knowledge of health consequences of smoking and attitudes and perceptions towards tobacco control and the role of doctors.

Two-sided tests of significance were based on the 0.05 level against a null hypothesis of no association, unless otherwise indicated.

\section{RESULTS}

\section{Demographic characteristics}

Owing to unavailability or absence at the time of survey, we were able to enrol a total of 855 doctors out of 1060, all of whom completed the questionnaires. The response rate was highest in Vientiane city (91.9\%), while the two lowest were Xiengkhouang (47.4\%) and Khammouane provinces (65.2\%).

Slightly more than half the sample $(52.9 \%)$ were males, with no variation by sex between regions. However, the number of doctors in the central region cohort was much larger than in the other two regions, reflecting their concentration in and around the capital. The age of respondents ranged from 24 to 65 years. About two-thirds had a basic bachelor's degree in medicine and $20.6 \%$ were specialists. A few (0.8\%) had a $\mathrm{PhD}$ and $11.2 \%$ had master's degrees. Among those who were in administration, $6.5 \%$ were directors or vice directors of provincial hospitals, and about a quarter were heads of divisions.

\section{Smoking patterns}

Overall, $9.2 \%$ of doctors surveyed were smokers ( $5 \%$ daily and $4.2 \%$ occasionally), $18.4 \%$ were ex-smokers and $72.4 \%$ had never smoked. Statistically significant differences in smoking were found by region, with rates lowest in the northern region $(p=0.049)$, and by sex $(17 \%$ for males vs $0.4 \%$ for females, $\mathrm{p}<0.001)$. Only two female doctors reported current smoking, while one had quit. Smoking rates (daily plus occasional) were highest $(16.9 \%)$ in the oldest cohort $(51-65)$, followed by $11 \%$ $(41-50), 7.8 \%(31-40)$ and $2.6 \%(24-30)(p<0.001)$.

\section{Smoking behaviour and expenditure}

No statistically significant differences emerged in smoking behaviour or expenditure by region. The large majority in each region started smoking by age 25 (mean $21.28 \pm 7.109$ years). Of the 79 current smokers, $43(54.4 \%)$ reported smoking $1-5$ cigarettes per day, $21(26.6 \%)$ smoked 6-10 cigarettes per day and 15 (19\%) smoked 11-20 cigarettes per day.

Forty three per cent smoked their first cigarette within 60 minutes after waking up and an additional 33\% within 60-180 minutes. Weekly expenditure on smoking had a large range (nearly 10-fold), with a mean of nearly 12000 kip (approx US\$1.38).

Among current smokers, $41.8 \%$ were around other smokers at places other than home or work for 4-7 days a week, with a mean of $3.3 \pm 2.6$. Most current smokers (84.8\%) said they wanted to quit and $74.7 \%$ indicated they had made a serious attempt to do so during the last year.

\section{Smoking-related knowledge, attitudes and perceptions}

Table 1 summarises responses to statements that were correct or deemed 'positive' about smoking-related knowledge and attitudes or perceptions, respectively, among current smokers, exsmokers and never smokers. Across all groups, including current smokers, over $90 \%$ gave the desired responses on 17 of a total 25 items.

There were high knowledge levels on $6 / 10$ questions. Proportions answering correctly were lower on neonatal and maternal health questions, and nearly half of every group was unaware that tobacco kills more people than illegal drugs, AIDS and road accidents combined. The only one reaching statistical significance related to the similar addictive potential of tobacco and heroin, answered correctly by just over two-thirds of smokers versus over four-fifths of the other groups $(p=0.003)$.

High levels of positive attitudes towards tobacco control-including bans on smoking in public places and healthcare facilities-were expressed by all groups except for banning of sports sponsorship, although even here a majority concurred. Smokers were less likely to endorse advertising bans $(p<0.00)$ and large health warnings on packs $(p=0.01)$, but over 
Table 1 Doctors' tobacco-related correct knowledge and positive attitudes and perceptions, by smoking status $(n=855)$

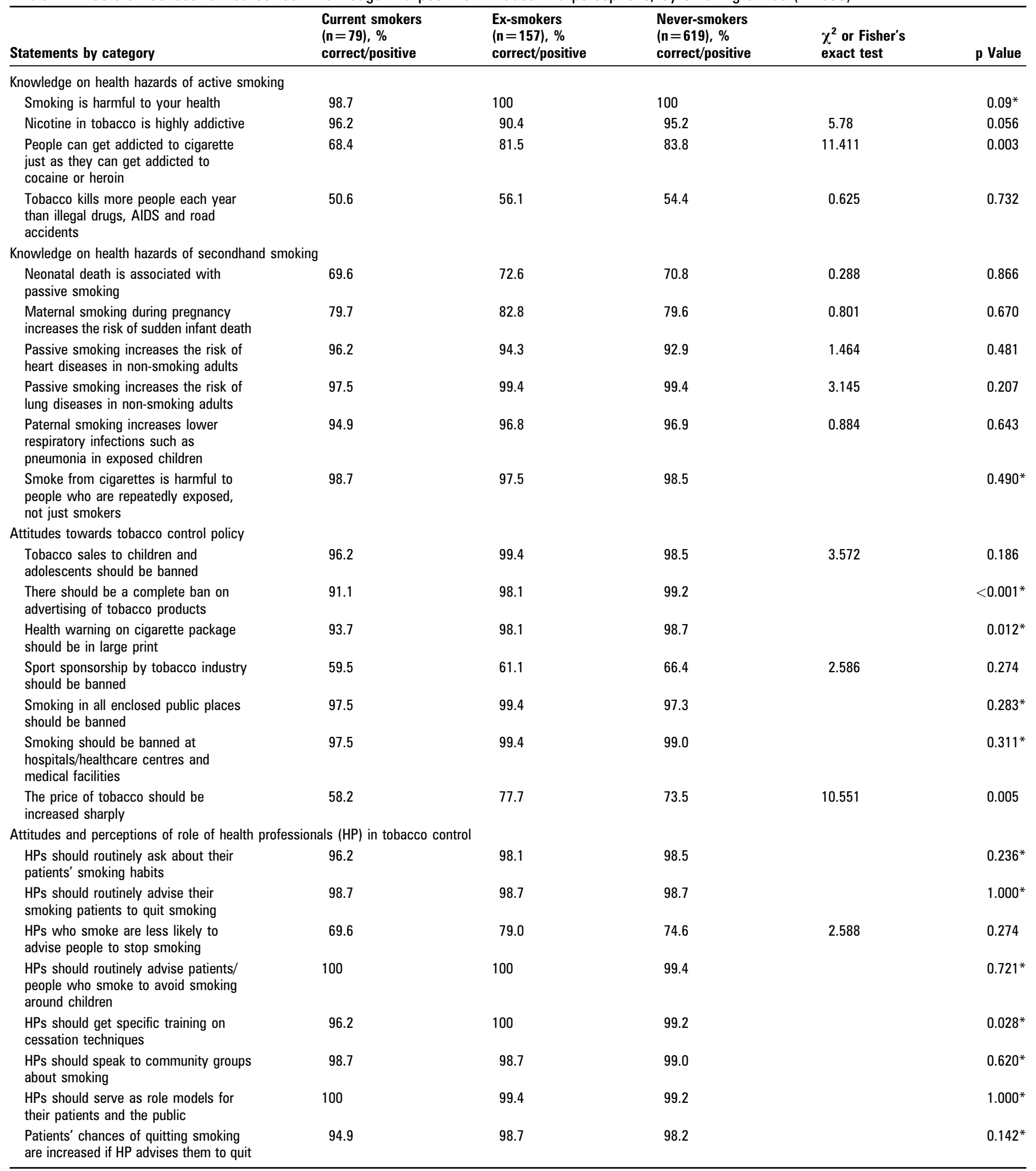

Current smokers include daily and occasional smokers; Never-smokers are those who have never smoked.

*For values less than 5 , Fisher's exact test was used.

91\% were supportive of each. 'Sharply' increasing the price of tobacco was supported by significantly fewer smokers, though still a majority $(58.2 \%)$, versus ex-smokers and never-smokers $(77.7 \%$ and $73.5 \%$, respectively) $(\mathrm{p}<0.005)$.

In relation to perceptions of the role of health professionals, all subgroups concurred at high levels $(94.9 \%+)$ that they 'should' actively support cessation with patients and community, and acknowledged their symbolic value as role models. Rather lower levels of agreement (between two-thirds and fourfifths) were found for the statement that health professionals who smoke 'are less likely to advise people to stop smoking', with no significant differences by smoking status. Smokers were 
less likely than others to agree health professionals should get special training on cessation techniques $(p=0.028)$, but this must be viewed against their very high rates of endorsement $(96.2 \%)$ on this item. The same caution should be applied in relation to apparent differences in several attitude questions (table 1).

\section{Workplace tobacco-related policies}

Table 2 presents responses provided by a subset ( $n=691,80.8 \%$ ) of the sample who reported being aware of smoking-related policies (or their absence) in their workplaces, which included clinical facilities as well as administrative offices. No significant differences in policy were found on the basis of smoking status. Overall, a third said their workplace had no official policy, but more than half $(57.3 \%)$ stated that smoking is 'not allowed' at all on the premises. However, only $35.7 \%$ said bans were 'always enforced'. Virtually all (98\%) said cigarettes were not sold 'inside' hospitals/offices, while a smaller proportion (79.2\%) reported that selling tobacco did not occur 'near' their workplaces. When asked about smoking policy for indoor public or common areas, $45.3 \%$ mentioned that smoking was allowed in some of these places.

Table 3 relates to training on smoking cessation techniques among the entire sample. Three-quarters had received no training, nor was training routinely offered at any professional stage. A bare $9.5 \%$ got such training during medical school. When training occurred, it was conducted most frequently in the workplace (16.7\%), followed by at conferences $(12.7 \%)$. Just $9.5 \%$ overall had been given any training on ways to deliver messages on the needs and benefits of quitting.

A total of $668(78 \%)$ had ever delivered cessation support to patients. So-called 'traditional remedies' to quit were employed by only a small fraction (6.6\%); over three-quarters used counselling, followed by self-help materials $(60.1 \%)$. Just over onethird suggested nicotine patches or gum. Smokers were significantly less likely to report having advised patients to quit in the previous 30 days $(p=0.017)$ or offered information on the health benefits of cessation $(p=0.023)$ than ex-smokers or non- smokers. Despite being involved in cessation, nearly threequarters of the subsample did not feel at all prepared to support their patients. Only one-fifth had ever taken part in a formal anti-tobacco campaign or conference.

\section{Determinants of smoking}

As noted above, logistic regression was undertaken to identify factors associated with current smoking among male doctors after controlling for confounding. Regression analysis found that, with each year's increase in age, the odds of smoking increased by $3.8 \%(p=0.028)$. Odds of smoking were inversely related to more positive attitudes towards tobacco control $(p=0.001)$. Factors not found to be significantly associated after regression analysis included levels of education or position, experience in providing cessation support, knowledge of the health consequences of tobacco or having smoking bans in workplaces.

\section{DISCUSSION}

The preamble to the 2003 WHO Framework Convention on Tobacco Control ${ }^{16}$ (ratified by Laos in 2006) notes the significant potential role of health professionals. Doctors are uniquely placed because they are generally seen as trusted sources of information and role models; thus, their behaviour can send non-verbal messages are either pro-tobacco or anti-tobacco. There is some historical evidence from high-income countries that declines in smoking among doctors were typically followed by declines in community prevalence. ${ }^{17}$

This is the first nationwide study of smoking-related practices, knowledge, attitudes and perceptions among medical doctors in Lao PDR, a low-income South East Asian nation. The 2007 study found the prevalence of current smoking in doctors was $9.2 \%$ (17.3\% in males and $0.4 \%$ in females), compared to national adult rates of $40.3 \%(67.7 \%$ in males and $16 \%$ in females) reported in a 2003 survey. ${ }^{11}$ The very high prevalence of community smoking in Laos poses a challenge for the country's policy-makers and health professionals, including doctors,

Table 2 Workplace smoking practice and policy by smoking status among those aware of smoking policy $(\mathrm{n}=691)$

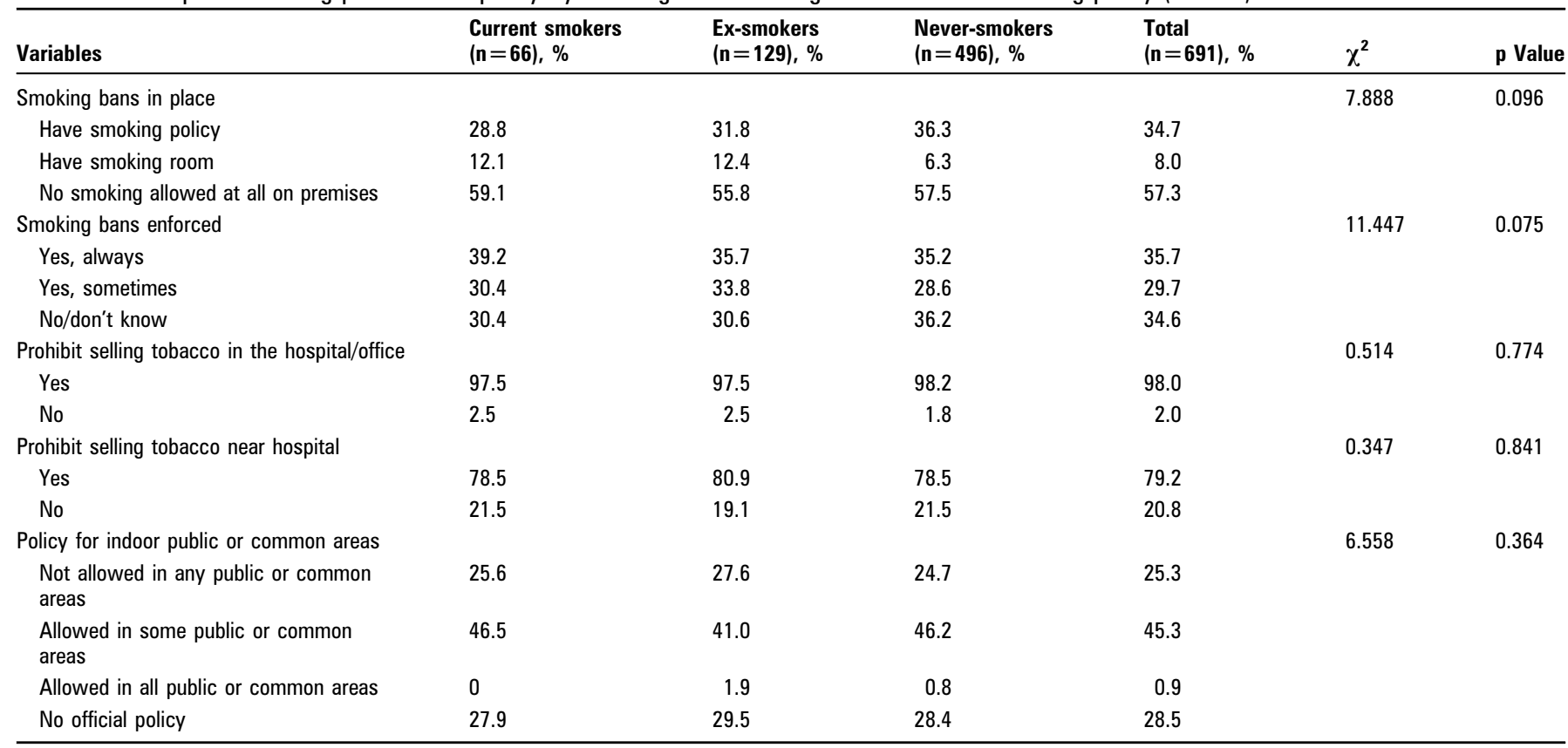


Table 3 Training on smoking cessation by smoking status $(n=855)$

\begin{tabular}{|c|c|c|c|c|c|c|}
\hline Variables & $\begin{array}{l}\text { Current smokers } \\
(n=79), \%\end{array}$ & $\begin{array}{l}\text { Ex-smokers } \\
(n=157), \%\end{array}$ & $\begin{array}{l}\text { Never-smokers } \\
(\mathrm{n}=619), \%\end{array}$ & $\begin{array}{l}\text { Total } \\
(\mathrm{n}=855), \%\end{array}$ & $\chi^{2}$ & p Value \\
\hline \multicolumn{5}{|c|}{ Ever received formal training on smoking cessation approaches } & 2.580 & 0.275 \\
\hline Yes & 23.4 & 28.7 & 20.3 & 24.1 & & \\
\hline \multicolumn{5}{|c|}{ Received formal training during medical school } & 0.452 & 0.798 \\
\hline Yes & 7.6 & 10.8 & 9.4 & 9.5 & & \\
\hline No & 92.4 & 89.2 & 90.6 & 90.5 & & \\
\hline No & 84.1 & 79.5 & 83.7 & 83.3 & & \\
\hline \multicolumn{5}{|c|}{ Received formal training as part of specialist training } & 8.174 & 0.017 \\
\hline Yes & 11.6 & 8.3 & 4.1 & 5.3 & & \\
\hline No & 88.4 & 91.7 & 95.9 & 94.7 & & \\
\hline \multicolumn{5}{|c|}{ Received formal training at conference } & 0.120 & 0.942 \\
\hline Yes & 11.6 & 12.2 & 13.0 & 12.7 & & \\
\hline
\end{tabular}

whose much lower smoking rates implies a real potential for their contribution to tobacco control.

Smoking rates among doctors vary between countries, and by sex and age. In their review of studies from 1974 to 2004, Smith and Leggat ${ }^{14}$ found rates as low as $2-4 \%$ in Australia, the USA and Britain in the survey's final decade. Recent figures were generally much lower in high-income compared to low and middle-income countries. Indeed, a 1996 study in China found doctors' rates had actually increased in previous years to $61 \%$ (males) and 12\% (females), although much lower figures were found in a 2003 study: 32\% (males) and 0\% (females). ${ }^{14}$ A 2004 study in doctors in Yerevan, Armenia, ${ }^{18}$ found current rates in males were $55.3 \%$ and in females $17.3 \%$. Rates in Japan's doctors in 1983 were 45\% (males) and 9\% (females); from 1994 they have hovered around $24 \%$ (males) and $7 \%$ (females). ${ }^{14}$ The enormous disparity between male and female doctors' tobacco use in our study (as found throughout Asia, among other regions) indicates the importance of gender norms in encouraging or discouraging uptake of smoking. ${ }^{19} 20$

Most studies in Smith and Leggat's review showed smoking more common among older doctors; however, in China, Japan and Mexico it was the reverse. ${ }^{14}$ Our study fit the norm, with odds of smoking increasing with age $(p=0.028)$. Highest rates were found in the oldest cohort (51-65: 16.9\%). The very low rates in the youngest (24-30 years: $2.6 \%$ ) offers hope that an important shift has occurred in a bell weather population, suggesting further declines may occur among Lao doctors over time, as well as at the community level.

Despite the potential impact of doctors in tobacco control, Smith and Leggat's review concluded that in much of the world doctors were not yet maximising their efforts. ${ }^{14}$ Impediments to involvement may comprise personal smoking status, knowledge and levels of confidence about supporting cessation. Our study suggests that major impediments for Lao doctors are relatively unlikely to arise in terms of prevalence, given their much lower smoking rates compared to the community. Knowledge of tobacco dangers was exceptionally high, overall. The few weak points are worthy of attention, in particular relatively poor recognition of the large mortality toll of tobacco, including the impact on neonatal and infant deaths through maternal exposure to secondhand smoking. It was concerning but not surprising to see that smoking doctors were significantly less likely than non-smokers to agree that the addictive power of tobacco rivals that of heroin, possibly reflecting unease over comparisons being drawn between their (legal) habit and an illicit one that is highly stigmatised in Laos.

Lao doctors' attitudes towards tobacco control were generally very positive ${ }^{10}$ including supporting bans on smoking in public places and healthcare facilities. However, there was relatively less endorsement (although still a majority) of banning sports sponsorship, and steep increases in the price of tobacco, which is known to be particularly effective in reducing consumption. The latter was significantly less likely to be supported by smokers $(p<0.005)$. Overall, those with less positive attitudes towards control of tobacco were associated with increased odds of smoking $(\mathrm{p}=0.001)$.

A study by Ohida et $a l^{21}$ also suggests that non-smoking doctors have more unfavourable views towards smoking and are more active in encouraging patients not to smoke. Smoking doctors in our study were significantly less likely to have advised patients to quit ( $p=0.017)$ or offered information on the health benefits of cessation $(p=0.023)$ than ex-smokers or non-smokers. A 2004 study in Yerevan, Armenia, found many doctors smoked in front of patients (sending an ambiguous message), and smokers were less likely to ask patients about smoking or to perceive their own behaviour could influence patients. ${ }^{18}$ In Greece, Japan, Finland and Estonia-though not in Israelsmoking doctors were less likely to discuss tobacco use with patients or assist them in cessation. ${ }^{14}$

In practice, $78 \%$ of doctors in Laos claim they are already engaged in supporting cessation. However, helping individuals to quit requires skills. In our cohort, just $24 \%$ had been trained in this domain, and a mere $8.8 \%$ considered themselves 'well prepared' to assume the role, a figure even lower than the approximately one-third of doctors surveyed in Armenia. ${ }^{18}$ The 2005 Global Health Professionals Survey, conducted among students in health professional training in 10 countries, found nearly all respondents felt they should offer cessation advice, but just $5 \%-37 \%$ had undergone such training. ${ }^{7}$

WHO in 2008 reported that the vast majority of countries do not sufficiently support users who want to quit. Effective services include brief routine advice from health professionals, 
quitlines and medications. ${ }^{22}$ Brazil introduced a programme of brief advice and medications provided at no cost, which led to about 50000 smokers quitting over a few years, of whom $45 \%$ used medications and about $40 \%$ remained abstinent after four weeks. Brazil also has a government-sponsored quitline, which is advertised on all tobacco warnings and retail outlets. ${ }^{22}$

The inadequacy of cessation support is particularly evident in the finding that nearly $85 \%$ of Lao medical doctors who currently smoke said they wanted to quit, and three-quarters reported making a serious (but unsuccessful) attempt to do so in the past year, figures higher than those found among doctors in Syria, ${ }^{23}$ Italy or Japan. ${ }^{14}$ Some studies have found that fewer than $5 \%$ of self-quitters maintain their abstinence. ${ }^{24}$ This indicates that the success rate is minimal unless there are active antismoking programmes and specialised smoking cessation counselling. The general absence of these in $\operatorname{Laos}^{22}$ acts as a further impediment for these doctors (and their patients).

Although Laos has ratified the Framework Convention on Tobacco Control, it still has gaps in its national tobacco control efforts. A third of our sample said their workplace had no official policy. Although more than half (57.3\%) stated that smoking is not allowed at all on the premises, only $35.7 \%$ said bans were 'always enforced'. In addition to insufficiency in cessation counselling support, the WHO 2009 global report noted the following in relation to the Lao PDR:

- Relatively affordable cigarettes, even for a low-income country (most popular brand priced at about US\$0.57);

- Low rates of tobacco taxation (41\%) compared to, for example, Fiji (77\%) and Thailand (64\%);

- Nicotine replacement therapy and other cessation medication not commonly available;

- Irregular monitoring of prevalence in adults and youths; and

- Irregular and unevenly enforced bans on public smoking and industry promotion. ${ }^{12}$

\section{Limitations of the study}

One limitation of this study is its cross-sectional nature. Thus, causes and effects could not be examined. The target group of this study is medical doctors who are working in administration and treatment, including researchers and public health workers; hence generalisation of the findings cannot extend to other types of health professionals. It is possible that recall bias, or reluctance to acknowledge smoking behaviour, may have affected responses.

\section{What this paper adds}

- It provides the first comprehensive assessment of the prevalence and associated determinants of smoking among medical doctors in Lao PDR.

- It shows that prevalence of smoking among doctors was substantially lower than the general population and occurred almost exclusively among older males.

- Tobacco-related knowledge and attitudes and reported engagement in cessation support were generally very high, but the large majority lacked confidence in providing assistance for cessation, with few having undergone training.

- Willingness of doctors to take up their tobacco control role and the lower smoking rates among younger respondents offers an important window of opportunity to consolidate their knowledge, attitudes, skills and enthusiasm as cessation advocates and supports.

\section{Recommendations}

The study findings in relation to doctors' smoking prevalence, knowledge, attitudes and involvement in tobacco cessation work indicate a timely opportunity to engage them in tobacco control more actively, thus potentially making a significant contribution to tobacco use prevention and cessation. However, doctors will be constrained in reaching this potential without further support. To this end, we offer the following suggestions for consideration by the Lao Ministry of Health.

- Targeted cessation support for doctors to assist their quit attempts and bolster their image as role models for nonsmoking;

- Training programmes for doctors (and medical students) on brief advice and cessation counselling to enable them to support patients and community;

- Training programmes for lower level health professionals in cessation support to reach greater numbers of the Lao population;

- Expansion to all regions of nicotine replacement therapy and medications of proved effectiveness to aid cessation;

- Medical school and in-service education for doctors (and health professionals) on the health, financial and other costs of tobacco use;

- Raising consciousness for doctors and the broader community about the negative impacts of gender norms for men and boys that encourage tobacco uptake; and

- Implementation of FCTC measures of greatest impact on prevention and cessation of tobacco use, including price rises and strict enforcement of bans on smoking in workplaces and public spaces.

\section{Conclusion}

Doctors in Lao PDR, a low-income country where community smoking prevalence is high, are prepared to contribute to tobacco control programmes if equipped with the appropriate tools.

Acknowledgements The authors are grateful to Ms Menchi G Valesco from the Thai Health Promotion Foundation and would like to acknowledge Dr Maniphanh Vongphosy from ADRA, Lao PDR, for her active support in terms of logistics and communication, and the reviewer and editorial support from Tobacco Control.

Funding Grants from the Rockefeller Foundation and Thai Health Promotion Foundation.

\section{Competing interests None.}

Ethics approval This study was conducted with the approval of the National Ethica Review Board for Research, Ministry of Health, Vientiane, Lao PDR ref No 132/NECHR.

Contributors SV, study design, data collection, initial analysis and drafting manuscripts. MM further analysis, drafted modification and June 2010 revision. AP study design, data analysis and commenting drafts; $\mathrm{VH}$, data collection and review manuscript; SP, study design and data analysis; TT, study design writing and commenting drafts. All authors read and approved the final draft of the manuscript.

Provenance and peer review Not commissioned; externally peer reviewed.

\section{REFERENCES}

1. Lopez AD, Collishaw NE, Piha T. A descriptive model of the cigarette epidemic in developed countries. Tob Control 1994:3:242-7.

2. Fowler G. Educating doctors in smoking cessation. Tob Control 1993;2:5-6.

3. Foote JA, Harris RB, Gilles ME, et al. Physician advice and tobacco use: a survey of 1st-year college students. J Am Coll Health 1996:45:129-32.

4. Bialous SA, Sarna L. Sparing a few minutes for tobacco cessation: if only half of all nurses helped one patient per month quit smoking, more than 12 million smokers would overcome their addictions every year. Am J Nurs 2004; 104:54-60.

5. Ezzati M, Lopez AD, Rodgers A, et al; Comparative Risk Assessment Collaborating Group. Selected major risk factors and global and regional burden of disease. Lancet 2002;360:1347-60. 
6. Rodgers A, Ezzati M, Vander Hoorn S, et al. Distribution of major health risks: findings from the global burden of disease study. PLoS Med 2004;1:e27.

7. Centers for Disease Control. Tobacco use and cessation counseling. Global Health Professionals Survey Pilot Study, 10 Countries, 2005. MMWR 2005:54:505-9.

8. World Bank. Development data: Lao PDR at a glance. 2009; http://devdata. worldbank.org/AAG/lao aag.pdf.

9. Tanuwong NW, Tengrungsun S, Sing Menorath S, et al. Rural health care in developing countries: AUNP Family Medicine Training Curriculum Development Project. Asia Pacific Family Medicine, 2007;6. http://www.apfmj-archive.com/ afm4_3/afm23.htm\#T2.

10. Tomson T, Boupha K, Gilljam H, et al. Knowledge, attitudes and smoking behavior among Lao doctors. Southeast Asian J Trop Med Public Health 2003;34:213-19.

11. Ministry of Health and National Institute of Public Health. Lao World Health Survey 2004. State Printing Publisher, 2006.

12. World Health Organization. WHO Report on the Global Tobacco Epidemic, 2009: Implementing Smoke-Free Environments. Geneva: World Health Organization; 2009

13. World Health Organization. Gender, health and tobacco. Geneva: Department of Gender and Women's Health, World Health Organization, 2003.

14. Smith DR, Leggat PA. An international review of tobacco smoking in the medical profession: 1974-2004. BMC Public Health 2007:7:115.
15. World Health Organization. WHO urges health professionals to engage in Tobacco Control. World No Tobacco Day. 2005; http://www.who.int/mediacentre/news/ releases/2005/pr22/en/index.html (accessed 29 Jun 2008)

16. World Health Organization. Framework Convention on Tobacco Control. Geneva: World Health Organization, 2003.

17. Davis RM. When doctors smoke. Tob Control 1993:2:187-8.

18. Perrin P, Merrill R, Lindsay B. Patterns of smoking behaviour among physicians in Yerevan, Armenia. BMC Public Health 2006;6:139.

19. World Health Organization. Women and the Tobacco Epidemic: Challenges for the 21st century. Geneva: World Health Organization, 2001.

20. Morrow M, Barraclough S. Tobacco Control and gender in Southeast Asia. Part I: Malaysia and the Philippines. Health Prom Inter 2003;18:255-64.

21. Ohida T, Sakurai $H$, Mochizuki $Y$, et al. Smoking prevalence and attitudes toward smoking among Japanese physicians. JAMA 2001;285:2643-8.

22. World Health Organization. WHO report on the Global Tobacco Epidemic, 2008. The MPOWER Package. Geneva: World Health Organization, 2008.

23. Maziak W, Mzayek F, Asfar T, et al. Smoking among physicians in Syria: Do as I say, not as I do! Ann Saudi Med 1998;19:253-6.

24. Centers for Disease Control. Smoking cessation during previous year among adults - United States, 1990 and 1991. MMWR 1993:42:504-7. 